\title{
An Assessment of Transport Property Estimation Methods for Ammonia-Water Mixtures and Their Influence on Heat Exchanger Size
}

Kærn, Martin Ryhl; Modi, Anish; Jensen, Jonas Kjær; Haglind, Fredrik

Published in:

International Journal of Thermophysics

Link to article, DOI:

$10.1007 / \mathrm{s} 10765-015-1857-8$

Publication date:

2015

Document Version

Peer reviewed version

Link back to DTU Orbit

Citation (APA):

Kærn, M. R., Modi, A., Jensen, J. K., \& Haglind, F. (2015). An Assessment of Transport Property Estimation Methods for Ammonia-Water Mixtures and Their Influence on Heat Exchanger Size. International Journal of Thermophysics, 36(7), 1468-1497. https://doi.org/10.1007/s10765-015-1857-8

\section{General rights}

Copyright and moral rights for the publications made accessible in the public portal are retained by the authors and/or other copyright owners and it is a condition of accessing publications that users recognise and abide by the legal requirements associated with these rights.

- Users may download and print one copy of any publication from the public portal for the purpose of private study or research.

- You may not further distribute the material or use it for any profit-making activity or commercial gain

- You may freely distribute the URL identifying the publication in the public portal 


\title{
An Assessment of Transport Property Estimation Methods for Ammonia-Water Mixtures and their Influence on Heat Exchanger Size
}

\author{
M.R. Kærn · A. Modi · J.K. Jensen · \\ F. Haglind
}

Received: date / Accepted: date

\begin{abstract}
Transport properties of fluids are indispensable for heat exchanger design. The methods for estimating the transport properties of ammonia-water mixtures are not well established in the literature. The few existent methods are developed from none or limited, sometimes inconsistent experimental data sets, conducted for the liquid phase only. These data sets are usually confined to low concentrations and temperatures, which are much less than those occurring in Kalina cycle boilers.

This paper presents a comparison of various methods used to estimate the viscosity and the thermal conductivity of ammonia-water mixtures. Firstly, the different methods are introduced and compared at various temperatures and pressures. Secondly, their individual influence on the required heat exchanger size (surface area) is investigated. For this purpose, two case studies related to the use of the Kalina cycle are considered: a flue-gas-based heat recovery boiler for a combined cycle power plant and a hot-oil-based boiler for a solar thermal power plant.

The different transport property methods resulted in larger differences at high pressures and temperatures, and a possible discontinuous first derivative, when using the interpolative methods in contrast to the corresponding state methods. Nevertheless, all possible mixture transport property combinations used herein resulted in a heat exchanger size within $4.3 \%$ difference for the flue-gas heat recovery boiler, and within $12.3 \%$ difference for the oil-based boiler.
\end{abstract}

Keywords Ammonia-water $\cdot$ Heat transfer $\cdot$ Heat exchanger design $\cdot$ Kalina cycle Modeling $\cdot$ Transport properties $\cdot$ Zeotropic mixture

M.R. Kærn · A. Modi · J.K. Jensen · F. Haglind

Department of Mechanical Engineering, Technical University of Denmark, Nils Koppels Allé Bygn. 403, DK-2800 Kgs. Lyngby, Denmark

Tel.: +45 45254121

Fax: +4545935215

E-mail:pmak@mek.dtu.dk 
Nomenclature

Roman

$A$ area $\left(\mathrm{m}^{2}\right)$

$A_{\mathrm{t}}$ total outer surface area $\left(\mathrm{m}^{2}\right)$

$c_{\mathrm{p}}$ specific heat capacity at constant pressure $\left(\mathrm{J} \cdot \mathrm{kg}^{-1} \cdot \mathrm{K}^{-1}\right)$

$c_{\mathrm{V}}$ specific heat capacity at constant volume $\left(\mathrm{J} \cdot \mathrm{kg}^{-1} \cdot \mathrm{K}^{-1}\right)$

$D$ outer diameter $(\mathrm{m})$, dipole moment (debyes)

$d$ inner diameter $(\mathrm{m})$

$F$ interaction parameter

$G$ mass velocity or mass flux $\left(\mathrm{kg} \cdot \mathrm{m}^{-2} \cdot \mathrm{s}^{-1}\right)$

$h$ heat transfer coefficient $\left(\mathrm{W} \cdot \mathrm{m}^{-2} \cdot \mathrm{K}^{-1}\right)$

$k$ thermal conductivity $\left(\mathrm{W} \cdot \mathrm{m}^{-1} \cdot \mathrm{K}^{-1}\right)$, Boltzmann's constant

$L$ length (m)

$\dot{m}$ mass flow rate $\left(\mathrm{kg} \cdot \mathrm{s}^{-1}\right)$

$M$ molecular weight $\left(\mathrm{g} \cdot \mathrm{mol}^{-1}\right)$

$N$ number of parallel circuits

$\mathrm{Nu}$ Nusselt number

$p$ pressure (bar)

Pr Prandtl number

$\dot{Q}$ heat flow rate $(\mathrm{kW})$

Re Reynolds number

$T$ temperature (K)

$U$ overall heat transfer coefficient $\left(\mathrm{W} \cdot \mathrm{m}^{-2} \cdot \mathrm{K}^{-1}\right)$

$V$ molar volume $\left(\mathrm{cm}^{3} \cdot \mathrm{mol}^{-1}\right)$

$x, \tilde{x}$ liquid mass and mole fraction

$y, \tilde{y}$ vapor mass and mole fraction

$Z$ bulk ammonia mass fraction

Greek

$\alpha$ rotational coefficient

$\rho$ molar density $\left(\mathrm{mol} \cdot \mathrm{cm}^{-3}\right)$

$\varepsilon$ energy-potential parameter

$\eta$ surface fin efficiency

$\kappa$ polar association parameter

$\mu$ dynamic viscosity ( $\mathrm{Pa} \cdot \mathrm{s})$

$\mu_{\mathrm{m}}^{\circ}$ low-pressure gas viscosity $(\mathrm{Pa} \cdot \mathrm{s})$

$\omega$ acentric fractor

$\Omega_{\mathrm{V}}$ viscosity collision integral

$\sigma$ molecular diameter $(\AA)$

Subscripts

a ammonia

c cold, critical

h hot

$\mathrm{m}$ mixture 
$\mathrm{r}$ reduced

w wall

Superscripts

* corresponding

$\wedge$ approximation

- mean

Abbreviations

EV evaporator

EC economizer

HRB heat recovery boiler

OBB oil-based boiler

SH superheater

\section{Introduction}

The zeotropic ammonia-water mixture has been used as a working fluid for decades in various applications utilizing low-grade heat such as absorption refrigeration systems, heat pumps, and power cycles. Reliable transport properties such as the viscosity and the thermal conductivity are always needed for the design of heat exchangers in such systems. The methods for estimating the transport properties of ammoniawater mixtures are not well established in the literature. The few existent methods are developed from none or limited, sometimes inconsistent experimental data sets, conducted for the liquid phase only. Conde-Petit [1] proposed a set of methods tailored for ammonia-water mixtures in absorption refrigeration applications and compared these methods with the available experimental data in the literature. More recently, experimental data sets were obtained by Liu et al. [2] for the liquid dynamic viscosity and by Cuenca et al. [3] and Shamsetdinov et al. [4] for the liquid thermal conductivity. Only the data set by Shamsetdinov et al. [4] included the full range of ammonia mass fractions and a large range of temperatures and pressures, whereas the former two data sets included small ranges of ammonia mass fractions (below 0.21), temperatures and pressures. Even the standard property databases like the NIST standardized reference database (REFPROP 9.12 [5]) do not allow for the transport property computation of polar mixtures such as ammonia-water. For these reasons, there is always a need to verify the influence of the transport property estimation methods used for a given heat exchanger design.

Both the plant efficiency and the cost (heat exchanger size) are important when comparing an ammonia-water based system with other thermal energy systems. One of the main benefits of using the ammonia-water mixture as the working fluid is the possibility of temperature matching between the heat source/sink and the working fluid, thus decreasing thermal irreversibilities. In turn, the required heat transfer surface area might increase because of a smaller temperature difference between the fluids and influence negatively in the eventual economic advantage of a more effective plant [6]. Additionally, the mixture boiling heat transfer coefficients are typically less than their pure counterparts $[7,8]$, thus leading to an even higher required heat 
transfer surface area and cost. The boiling heat transfer degradation is mainly due to the additional mass transfer resistance in the nucleate boiling region and changes in the transport properties in the convective boiling region [7]. A reliable estimation of the transport properties and thus the heat exchanger sizes are therefore imperative for a full economic comparison of an ammonia-water based system with other systems. When no validated transport property methods exists in the open literature, the influence of using different standard estimation methods must be evaluated.

To the authors' knowledge, the only previous study in which the influence of different transport property methods are evaluated for ammonia-water systems, is the study by Thorin [9]. The influence of two thermodynamic property correlations $[6,10]$ and two transport property correlations $[6,11]$ for the liquid and the vapor viscosity and thermal conductivity was assessed, and the differences in the heat exchanger surface areas were as large as $24 \%$ and $10 \%$, respectively, for individual heat exchangers in their Kalina cycle configuration. Furthermore, Thorin [9] argued that several studies may be found in the literature in which the heat transfer processes of ammonia-water mixtures are involved, but they seldom report on the specific transport property methods used therein. Additionally, the method to evaluate the pure component transport properties, if needed by the mixture correlation, is typically not reported. The pure components might also be in different phases (liquid or vapor) compared with the mixture phase at the mixture temperature and pressure. Therefore, restriction should be imposed to ensure that the pure component estimations are in the same phase as the mixture.

This paper compares various known transport property methods for the estimation of the liquid and the vapor viscosity and thermal conductivity of ammonia-water mixtures, and their individual influence on the required heat exchanger surface area during numerical design. The objective is to clarify whether the different transport property methods have a significant influence on the designed heat exchanger size. Two Kalina cycle case studies are considered for this purpose: a flue-gas-based heat recovery boiler (HRB) for a combined cycle power plant and a hot-oil-based boiler (OBB) for a solar thermal power plant. Moreover, the two cases represent boilers with either poor or good heat transfer characteristics on the secondary side. The boiler is usually the largest component in the Kalina cycle, taking up about half of the total surface area [9] and destroying the most exergy [12]. In contrast to the work by Thorin [9], several transport property estimation methods will be analyzed by simulating each possible combination individually, and a suitable two-phase heat transfer correlation will be used instead of the fixed constant coefficient assumption by Thorin [9]. Finally, a discretized model is used that takes into account the local properties and heat transfer in the heat exchangers.

In total, 12 transport property methods are used during the numerical design for the liquid and the vapor viscosity and thermal conductivity estimates. The actual estimates are graphically presented at various ammonia mass fractions, temperatures and pressures, and compared to a few experimental data. All possible combinations of transport property methods are simulated at different ammonia mass fractions and pressures in order to include several design conditions.

The outline of the paper is as follows: Sect. 2 introduces the transport property estimation methods and correlations that have historically been proposed for ammonia- 
water mixtures. Sect. 3 introduces the design models of the two case studies. Sect. 4 presents the estimated heat exchanger sizes when using different transport property methods. Finally, the results are discussed in Sect. 5 and followed up by the conclusions in Sect. 6.

\section{Transport Properties}

Throughout this work, the NIST standardized reference database (REFPROP 9.12 [5]) has been used to evaluate the thermodynamic properties. The latest so-called "Ammonia (Lemmon)" fluid file is used to select the ammonia-water mixture [13]. The fluid file contains a refit of the ammonia equation of state that is compatible with the latest excess Helmholtz mixture model. The new ammonia-water mixture formulation is more stable and faster [14] while giving outputs that are very close to that of the earlier Tillner-Roth and Friend [10] formulation (REFPROP 9.0). For pure component transport properties, the same database is used while the critical mixture properties (temperature, pressure, and density) are evaluated using the experimentally established formulations by Sassen et al. [15].

Many transport property estimation methods, for both pure components and mixtures, have been gathered and described by Poling et al. [16]. The methods for mixtures may be categorized to be either interpolative methods (e.g. the set of methods proposed by Conde-Petit [1]) or corresponding state methods (e.g. the methods by Chung et al. [17, 18]). Interpolative methods make use of the pure component transport properties evaluated at the same pressure and temperature as the mixture, while the corresponding state methods are based on pseudo-critical parameters and do not require the pure component transport properties. A includes all of the equations that are used to estimate the transport properties used in this work, see Table 7 and 8, with the exception of the mixing rules and the constant coefficients used in the methods by Chung et al. $[17,18]$.

Interpolative methods may seem convenient using the mixture temperature and pressure for the pure components states, but are only directly applicable when the pure and the mixture states are recognized as either liquid or vapor. Fig. 1 shows the pressure-temperature curves of pure ammonia and water. To the left of the pure ammonia curve $(Z=1)$, both ammonia and water are in the liquid state (region 1$)$. To the right of the pure water curve $(Z=0)$, both ammonia and water are in the vapor state (region 3). In between the pure pressure-temperature curves, both liquid and vapor states may result for the mixture (region 2). This is determined by the composition and exemplified by indicating the bubble and dew curves at $Z=0.5$. In other words, pure ammonia is vapor and pure water is liquid in region 2 , however the mixture can be either liquid or vapor. The interpolative methods either fail or the pure state must be limited to be the same phase as the mixture phase.

El-Sayed [11] seems to be the only source in the literature that actually describes this grey zone using the interpolative methods. To solve the problem, El-Sayed [11] employs the corresponding state temperature for each component defined by

$$
T_{i}^{*}=T_{\mathrm{m}} \frac{T_{\mathrm{c} i}}{T_{\mathrm{cm}}}
$$




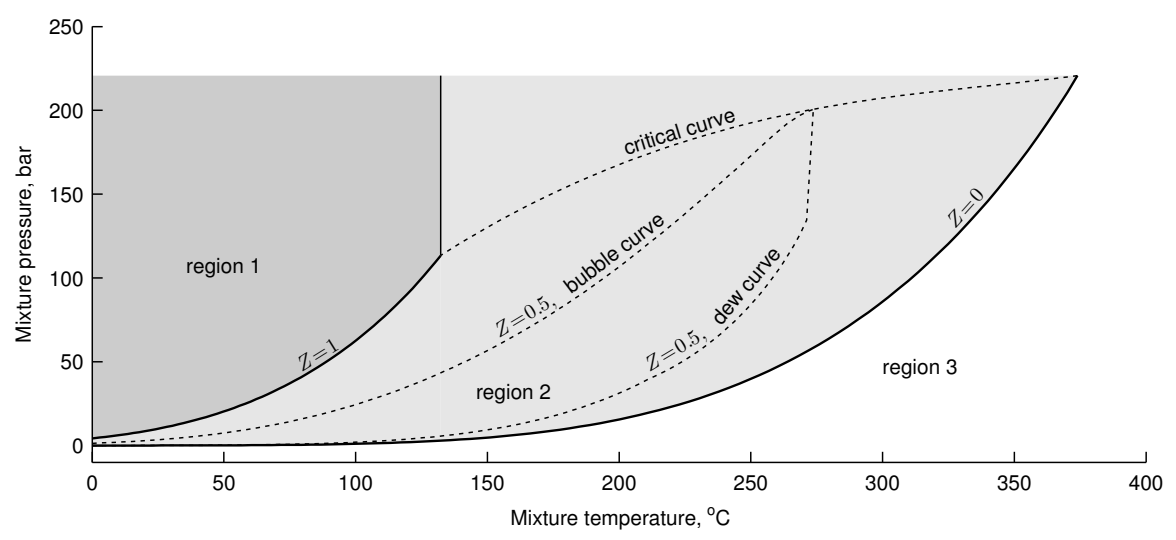

Fig. 1 Pressure-temperature curves for pure ammonia $(Z=1)$, pure water $(Z=0)$ and a mixture at $Z=0.5$ (bubble and dew curves). Region 1 (dark gray) is liquid for water, ammonia, and the mixture; Region 3 (white) is vapor for ammonia, water, and the mixture; Region 2 (light gray) is vapor for ammonia, liquid for water, but may be either vapor or liquid for mixture corresponding to composition

where $T_{\mathrm{m}}$ is the mixture temperature, $T_{\mathrm{c} i}$ is the critical temperature of component $i$ and $T_{\mathrm{cm}}$ is the critical temperature of the mixture. The method limits the pure component state to be below its critical temperature. However, sometimes such a "pure" corresponding state may lead to a non-existent pure state, e.g. at $T_{\mathrm{m}}=300 \mathrm{~K}$ and $Z=0.1$, the corresponding state temperature of ammonia becomes $300 \times(405.6 / 627.1)=194 \mathrm{~K}$, which is below the lower limit of ammonia in REFPROP. In other words, a general interpolation methodology does not exist. El-Sayed [11] used the corresponding state temperature to evaluate the liquid viscosity and thermal conductivity; however for the vapor viscosity and thermal conductivity, the mixture temperature and pressure were used. The corresponding state temperature was also used by Teja and Rice [19] for the estimation of liquid viscosity. Similarly, Conde-Petit [1] proposed the same corresponding temperature approach in his interpolation scheme, however again only for liquid transport properties.

All other interpolative methods to be introduced herein use mixture temperature and pressure for the pure component states. The fictive liquid ammonia and water vapor in region 2 are then evaluated as follows: For the pure liquid ammonia evaluation, we have limited the liquid state to be that of the saturated liquid at the same temperature as the mixture. It is justified by the fact that pressure has little effect on liquid viscosity and thermal conductivity. If the mixture temperature is above the critical temperature of ammonia, no liquid state of ammonia can be evaluated at the same temperature as the mixture, thus we have limited the liquid ammonia state to be that of the critical state. For the pure water vapor evaluation in region 2, we have limited the vapor state to be that of saturated water vapor at the same temperature as the mixture. For low pressure (dilute) gases this assumption holds true, but for high pressure (dense) gases the pressure/density effects become more important.

The strength of the corresponding state methods for mixtures (not to be confused with the pure corresponding state for interpolative methods) is that the pure component transport properties are not needed. In other words, such methods are purely 
a

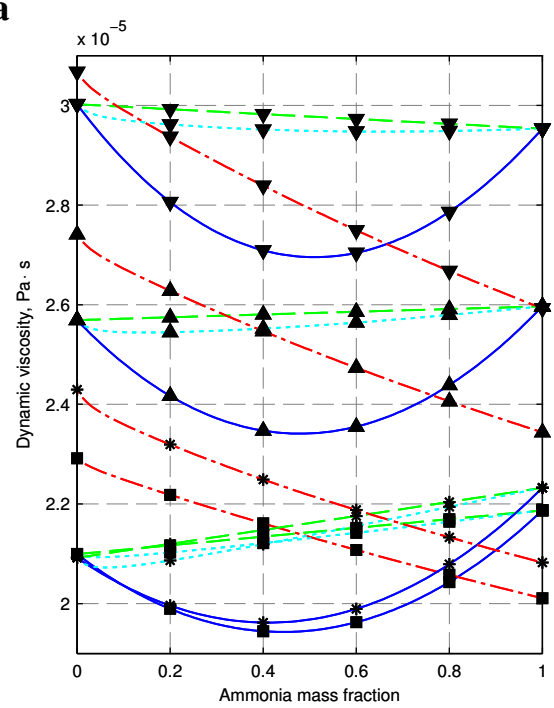

b

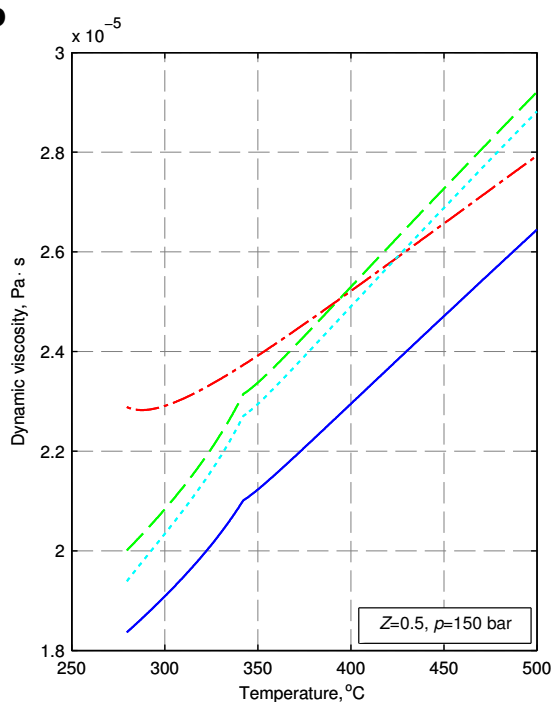

Fig. 2 Comparison of vapor viscosity methods. Curves (methods): —— Reichenberg [20]; — — Wilke [21]; - - - Chung et al. [17, 18]; --- - Chung et al. [17, 18] (composition averaged error). Symbols (conditions): $\boldsymbol{\nabla} T=325{ }^{\circ} \mathrm{C}, p=50 \mathrm{bar} ; * T=325^{\circ} \mathrm{C}, p=100 \mathrm{bar} ; \boldsymbol{\Delta} T=425^{\circ} \mathrm{C}, p=100$ bar; $\nabla T=525$ ${ }^{\circ} \mathrm{C}, p=100$ bar;

predictive and thus generally applicable, however they tend to give higher errors than the interpolative methods [16]. If pure component transport properties are available, the estimation can be improved by using a composition-averaged error of the pure component predictions.

\subsection{Vapor Viscosity}

Fig. 2 shows four different vapor viscosity methods all of which are described in Poling et al. [16]. The first two listed methods (Reichenberg [20] and Wilke [21], Eqs. 16 and 15) are simplifications of the Chapman-Enskog kinetic theory extended to mixtures and are interpolative. The third method is the corresponding state method of Chung et al. [17, 18] (Eq. 17). It is also based on the Chapman-Enskog kinetic theory and is applicable for both high and low pressure gas mixtures. The fourth method corrects the corresponding state method of Chung et al. [17, 18] by using the composition-averaged error of the pure component predictions.

It should be noted that Fig. 2a shows results obtained only in region 3 of Fig. 1 . In contrast, Fig. $2 \mathrm{~b}$ shows results in regions 2 and 3.

Fig. 2a shows that the vapor viscosity depends more on the temperature than on the pressure at these conditions. Changing the pressure from 50 to 100 bar at the same temperature $\left(325^{\circ} \mathrm{C}\right)$ does not have a significant effect on the pure component viscosities and the interpolative methods, whereas the method of Chung et al. $[17,18]$ indicates a slightly larger significance of pressure. The method of Reichenberg [20] 
is more complex than that of Wilke [21]. It suggests a parabolic trend, whereas Wilke [21] is almost linear with respect to composition. The latter method tends to be linear, because the interaction parameters $\left(F_{12}\right.$ and $\left.F_{21}\right)$ are close to unity for ammonia-water mixtures, as the viscosities and molecular weights are similar. The corresponding state method of Chung et al. $[17,18]$ results in a small error at the pure component states compared to the values suggested by REFPROP. The small error is considered to be reasonable for a fully predictive method. When improving that method by the composition-averaged error of the pure components, it suggests nearly the same linear trend as the method of Wilke [21]. The method of Wilke [21] has also been shown to perform well for other polar-polar compounds [16] which justifies its usage to some extent. The same method has been proposed by El-Sayed [11] and Conde-Petit [1] specific to ammonia-water mixtures.

Fig. $2 \mathrm{~b}$ shows the problem of a nonexistent pure water vapor in region 2. As already mentioned, we limited the water vapor to be that of the saturated vapor at the mixture temperature. For this reason, the methods that use the pure component vapor viscosities result in a $C^{1}$ discontinuity (discontinuous first derivative) when crossing from region 2 to 3 , i.e. at the saturation temperature of water $\left(342^{\circ} \mathrm{C}\right.$ at 150 bar). The discontinuity is not present in the corresponding state method of Chung et al. $[17,18]$ and highlights the strength of this fully predictive method. However, the discontinuity is small and vanishes at lower pressures.

\subsection{Liquid Viscosity}

Regarding the estimation of both pure and mixture liquid viscosity, there is no theoretical basis, and experimental data are particularly desirable. Fig. 3 illustrates four different liquid viscosity methods and their comparison to experimental data by Frank et al. [22], Liu et al. [2] and Pinewitsch [23]. The first two listed (Conde-Petit [1] and El-Sayed [11], Eqs. 7 and 8) have already been mentioned and are interpolative methods using the "pure" corresponding state temperature approach. Note that the method of El-Sayed [11] is misprinted in the original work, as pointed out by Thorin [9]. The third method, proposed in Handbuch der Kältetechnik [24] (Eq. 9), was explicitly developed for ammonia-water and based on a curve fit of experimental data. It uses mixture temperature and composition directly, thus the pure component viscosities are not required. The fourth method is a modified version of the Teja and Rice [19] method as used by Stecco and Desideri [6] (Eq. 10). The authors modified the method by using the actual mixture temperature in the evaluation of the pure component viscosities instead of the pure corresponding state temperature. Additionally, the interaction parameter $\psi$ was set to 8 , which has also been suggested by El-Sayed [11]. All these methods take advantage of the liquid viscosity being nearly independent of pressure; thus when the pure component viscosities are needed, the saturated liquid viscosity is used. All these methods are experimentally established, however the method by Conde-Petit [1] has been established most recently and was developed using the most number of experimental data points.

Fig. 3a shows that the methods correspond reasonably well to the experimental data at various ammonia mass fractions and temperatures, except the method by 
a

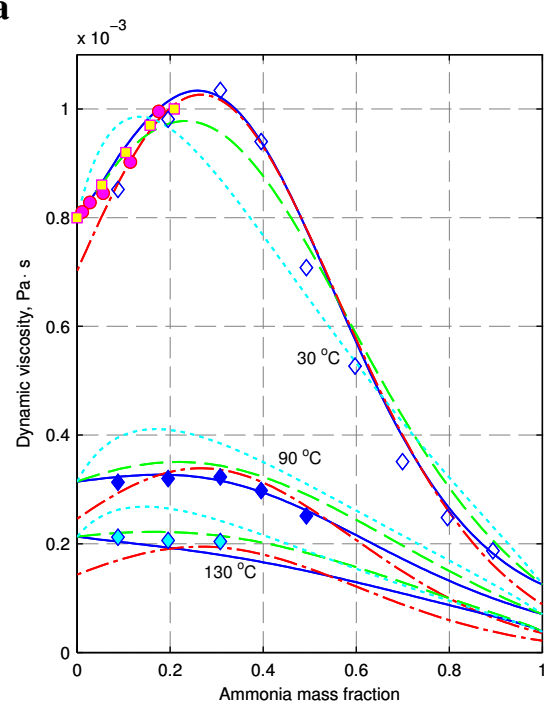

b

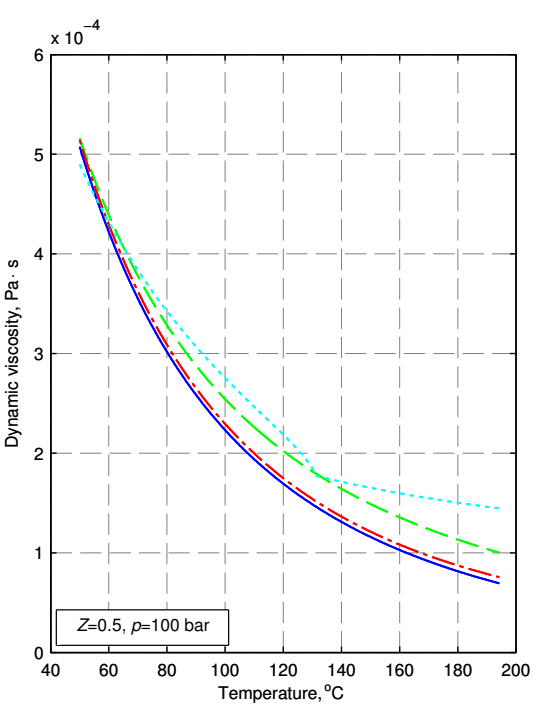

Fig. 3 Comparison of liquid viscosity methods and some measurements. Curves (methods): —— CondePetit [1]; - — El-Sayed [11]; - — - Handbuch der Kältetechnik [24]; - - - - Stecco and Desideri [6]. Symbols (measurements): $\square$ Frank et al. [22]; $\bullet$ Liu et al. [2]; $\diamond \diamond$ Pinewitsch [23]

Stecco and Desideri [6]. This method gives mostly overestimated values, but also underestimated values at low temperatures and ammonia mass fractions. Furthermore, the method outlined in Handbuch der Kältetechnik [24] gives errors at the pure component states. Note again that Fig. 3a shows results from region 1 in Fig. 1, meaning that both the mixture and the pure states are liquid. Fig. $3 \mathrm{~b}$ shows a temperature sweep from $50^{\circ} \mathrm{C}$ to the saturated liquid of the mixture at $Z=0.5$ and $p=100$ bar (region 1 to 2). Again, a $C^{1}$ discontinuity is seen in the method of Stecco and Desideri [6] as the pure ammonia state is limited to that of the critical temperature of ammonia $\left(132.4^{\circ} \mathrm{C}\right)$.

\subsection{Vapor Thermal Conductivity}

Fig. 4 shows four different vapor thermal conductivity methods all of which are described in Poling et al. [16]. The first method listed is a simple mole fraction average interpolation (Eq. 18). Poling et al. [16] does not recommend any specific thermal conductivity method to be applicable for polar compounds. However, for mixtures in which size and polarities do not differ greatly, the authors suggest the use of the linear mole fraction average. The second method is a modification of the Mason and Saxena [25] method (Eq. 19). Poling et al. [16] showed that this method with minor modifications becomes identical to the interpolative method of Wilke [21] for mixture viscosity with the same interaction parameters and interpolation equation. The same method was also suggested by Stecco and Desideri [6], El-Sayed [11], and CondePetit [1]. Again, because the molecular weights and the viscosities are similar for 
$\mathbf{a}$

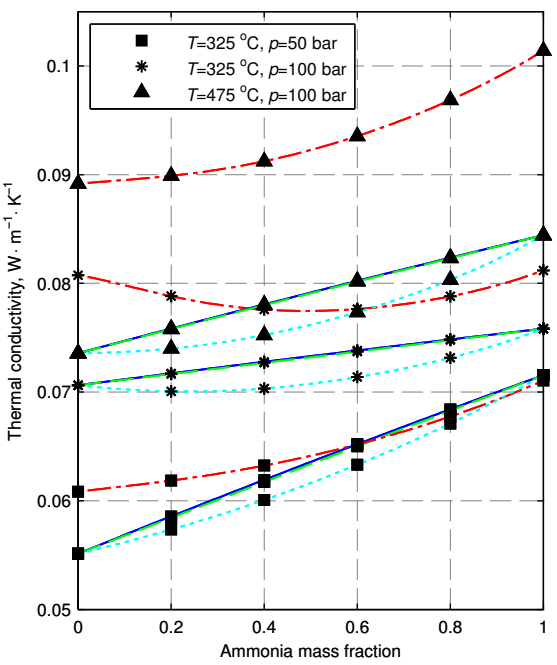

b

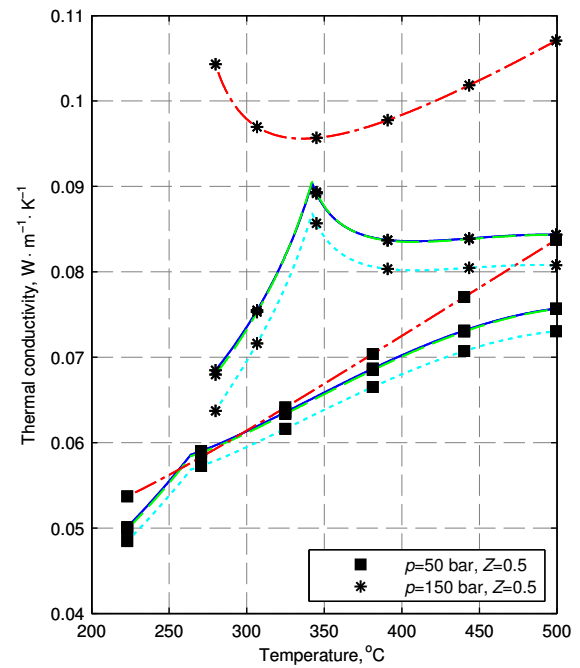

Fig. 4 Comparison of vapor conductivity methods. Curves (methods): - Mole-fraction average; - - Mason and Saxena [25]; - - - Chung et al. [17, 18]; - - - - Chung et al. [17, 18] (composition averaged error)

ammonia and water, the interaction parameters $\left(F_{12}\right.$ and $\left.F_{21}\right)$ are near unity and the method exhibits a linear trend. The third method listed is the mixture corresponding state method of Chung et al. [17, 18] applicable for both high and low pressure gas mixtures (Eq. 20). It is purely predictive and correlates the so-called Eucken-factor $\left(k / \mu c_{\mathrm{v}}\right)$, thus viscosity must be predicted first. The method is also described in Poling et al. [16] and was not recommended for polar mixtures. However, Chung et al. $[17,18]$ claim their method to be generally applicable and use a diffusion parameter $(\kappa)$ specific to each polar compound. The fourth method corrects the corresponding state method of Chung et al. [17, 18] by using the composition-averaged error of the pure component predictions.

Fig. 4a shows that the vapor thermal conductivity is a function of both temperature and pressure for both pure components as well as the mixture. Fig. 4a shows results obtained from region 3 in Fig. 1. As already mentioned, the method of Wilke [21] produces similar results as the mole fraction average for vapor viscosity. Similarly, the Mason and Saxena [25] method produces a linear trend and coincides with that of the mole fraction average for vapor thermal conductivity. The corresponding state method of Chung et al. [17, 18] gives similar results compared to the interpolative methods at 50 bar, but gives higher values at higher pressures and temperatures. The composition-averaged error method gives a nearly linear function of composition, and essentially verifies the recommendations by Poling et al. [16], i.e. the use of a mole-fraction average.

Unfortunately, sweeping through region 2 to 3 of Fig. 1 results in a much larger $C^{1}$ discontinuity using the interpolative methods for the thermal conductivity than for the viscosity (see Fig. 2b). This is more pronounced at higher pressures. Compared to 

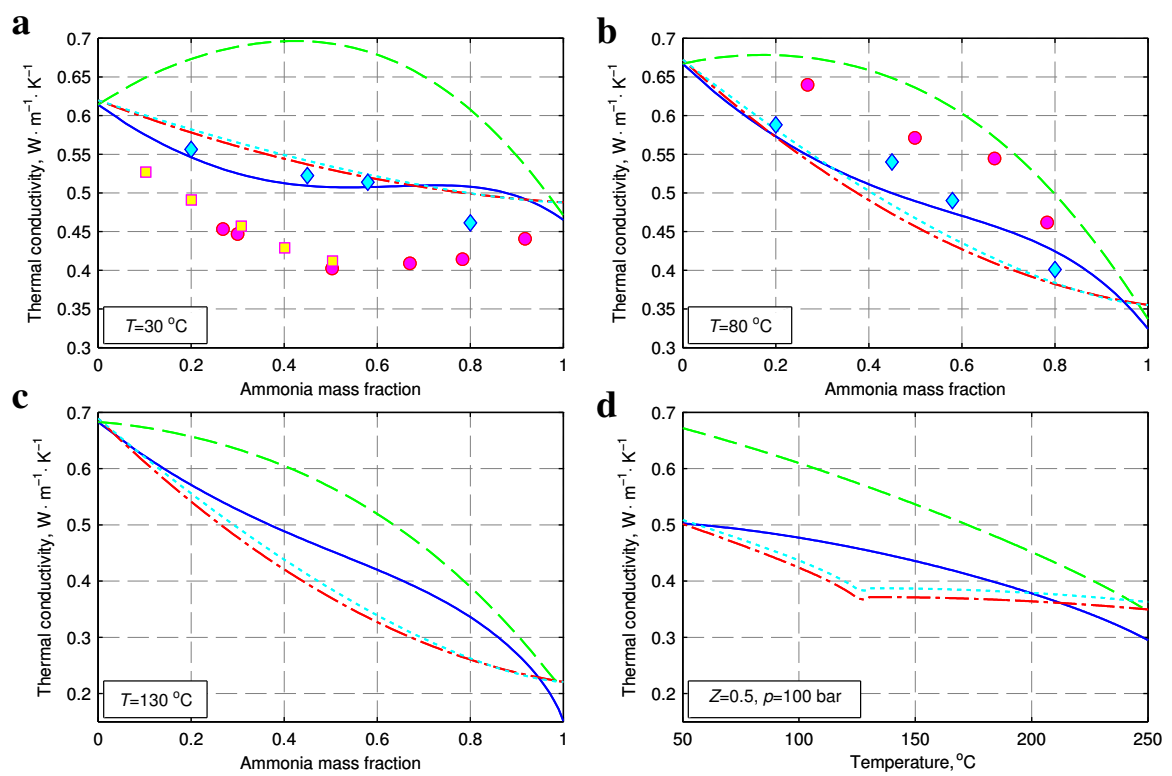

Fig. 5 Comparison of liquid thermal conductivity methods and some measurements. Curves (methods): — Conde-Petit [1]; — - El-Sayed [11]; - — - Filippov [27]; - - - - Jamieson et al. [28]. Symbols (measurements): $\square$ Cuenca et al. [3]; $\bullet$ Shamsetdinov et al. [4]; $\diamond$ Baranov et al. [26]

the corresponding state method of Chung et al. [17, 18], it is likely to be a nonphysical discontinuity.

\subsection{Liquid Thermal Conductivity}

Similar to the estimation of liquid viscosity, there are no theoretically established methods for the estimation of liquid thermal conductivity, and experimental data are particularly desirable. Fig. 5 illustrates four different liquid thermal conductivity methods and their comparison to experimental data by Cuenca et al. [3], Shamsetdinov et al. [4] and Baranov et al. [26]. The experimental data sources indicate a scattered picture. Firstly, the data by Baranov et al. [26] are not aligned with the others. Secondly, the data by Shamsetdinov et al. [4] indicate a significant increase with temperature. Moreover, a convex function of mass fraction is observed at $30^{\circ} \mathrm{C}$, whereas a concave function of mass fraction is observed at $80^{\circ} \mathrm{C}$, according to the data by Shamsetdinov et al. [4].

Regarding the estimation methods, the first two listed (Conde-Petit [1] and ElSayed [11], Eqs. 11 and 12) are interpolative methods using the saturated corresponding state temperature approach. The third and fourth listed methods (Filippov [27] and Jamieson et al. [28], Eqs. 13 and 14) are interpolative methods using mixture temperature and pressure for the pure component thermal conductivities, even though the pressure effects are negligible and the saturated liquid temperature could have been used directly. 
Refering to Figs. 5a, 5b and 5c, the thermal conductivity of water exhibits a weak dependence on temperature, while the thermal conductivity of ammonia decreases with temperature. In fact water has a maximum in liquid thermal conductivity close to $130-135^{\circ} \mathrm{C}$, before decreasing at higher temperatures. Note that water at these temperatures and pressures is much subcooled. The figures show that the method of El-Sayed [11] results in the concave function, the methods of Filippov [27] and Jamieson et al. [28] result in the convex function, whereas the method of Conde-Petit [1] results in an S-shape function. It is difficult to judge which method performs the best. At $80^{\circ} \mathrm{C}$, it may be argued that the method of El-Sayed [11] performs the best, however at $30^{\circ} \mathrm{C}$ the method overestimates significantly (around $75 \%$ at $Z=0.5$ compared to Cuenca et al. [3] and Shamsetdinov et al. [4]). Overall, the method by Conde-Petit [1] seems to perform the best and result in values close to the methods by Filippov [27] and Jamieson et al. [28]. Poling et al. [16] have shown that especially the method of Filippov [27] gave good results for some aqueous polar mixtures other than ammonia-water. However, it is only the method of Conde-Petit [1] that has been experimentally established even though these measurements also had remarkable inconsistencies [1].

Fig. $5 d$ shows the transition from region 1 to 2 of Fig. 1 at $p=100$ bar and $Z=0.5$. Again, the limitation of the pure ammonia state to be liquid at its critical temperature shows a $C^{1}$ discontinuity in the methods of Filippov [27] and Jamieson et al. [28]. In contrast, the corresponding state temperature approach by El-Sayed [11] and CondePetit [1] is smooth.

\section{Model Development}

This section presents the models of the HRB and the OBB, and explains the implementation briefly. Then the HRB model is verified with earlier model results, and the numerical convergence is duly analyzed for both models. The models are implemented in Dymola 2014 [29] using the Modelica language. All transport property methods used herein are freely available in the Modelica-REFPROP interface [30].

\subsection{HRB Model}

A sketch of the HRB is shown in Fig. 6. The HRB is recognized as a once-through boiler having the cold fluid flowing inside a vertical tube bundle with external circular fins and the hot fluid flowing in a counter-cross flow arrangement. The hot fluid is simplified to be the product of a stoichiometric burning of methane and air $(21 \%$ $\mathrm{O}_{2}, 79 \% \mathrm{~N}_{2}$ ). The properties of the flue-gas are evaluated using the Modelica.Media library, i.e. an ideal gas mixture. The inlet gas temperature and mass flow rate are $524^{\circ} \mathrm{C}$ and $100 \mathrm{~kg} \cdot \mathrm{s}^{-1}$, respectively. The cold medium is the ammonia-water mixture with an ammonia mass fraction, inlet temperature, and pressure of $0.7,25^{\circ} \mathrm{C}$ and 40 bar, respectively. The pinch point temperature difference is $15 \mathrm{~K}$, and the approach temperature difference (hot fluid inlet, cold fluid outlet) is $20 \mathrm{~K}$. The ammonia mass fraction and pressure are varied from 0.5 to 0.9 and from 40 to 100 bar, respectively, which are typical inlet conditions of the boiler in Kalina cycles [12, 31, 32]. 


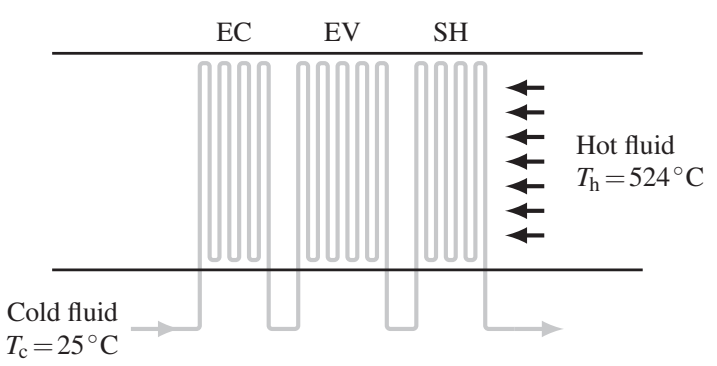

Fig. 6 Heat recovery boiler

Table 1 Main geometry of the HRB

\begin{tabular}{lr}
\hline Tube length & $5 \mathrm{~m}$ \\
Inner tube diameter & $34 \mathrm{~mm}$ \\
Outer tube diameter & $40.64 \mathrm{~mm}$ \\
Fin density & $236 \mathrm{~m}^{-1}$ \\
Fin height & $20 \mathrm{~mm}$ \\
Fin thickness & $1.5 \mathrm{~mm}$ \\
Transverse tube pitch & $100 \mathrm{~mm}$ \\
Longitundinal tube pitch & $90 \mathrm{~mm}$ \\
Tubes per row & 60 \\
Frontal area & $30 \mathrm{~m}^{2}$ \\
Minimum free flow area & $13.56 \mathrm{~m}^{2}$ \\
\hline
\end{tabular}

With these assumptions, for a given ammonia mass fraction, the temperature profiles of both fluids as a function of the heat flow rate may be constructed, see Fig. 7 . In other words, the heat exchange in the economizer, the evaporator, and the superheater is known from these design conditions, while the heat exchanger surface area remains unknown.

To compute the required heat exchanger surface area, a simple model was developed that computes the local heat transfer by discretization with respect to the heat flow rate. The specific geometry of the HRB is according to the case study by Stecco and Desideri [6] and listed in Table 1, whereas the applied heat transfer and pressure drop correlations are shown in Table 2. The two-phase boiling heat transfer correlation was originally developed for pure fluids, but has been shown to agree reasonably well for refrigerant mixtures [7]. The boiling heat transfer effect is recommended as further study in the discussion of the paper. Additionally, the tube layout is staggered, and the tube material is steel (constant thermal conductivity of $42 \mathrm{~W} \cdot \mathrm{m}^{-1} \cdot \mathrm{K}^{-1}$ is assumed).

Note that the frontal area of the hot fluid is fixed by the transverse tube pitch, the number of tubes per tube row (number of tubes in transverse direction), and each individual tube length. This allows for computation of the local maximum hot fluid velocity, local Reynolds number, and thus a hot fluid local heat transfer coefficient and frictional pressure gradient, both of which depend only on changes in the hot fluid properties throughout the heat exchanger.

By assuming that the number of parallel cold fluid circuits $N$ equals the number of tubes per tube row, the cold fluid mass flux (or mass velocity) is known throughout 
Table 2 Heat transfer and pressure drop correlations

\begin{tabular}{|c|c|}
\hline \multicolumn{2}{|l|}{ Hot fluid } \\
\hline Heat transfer & Briggs and Young [33] \\
\hline Fin efficiency & Shah and Sekulic $[34]^{a}$ \\
\hline Friction & Robinson and Briggs [35] \\
\hline \multicolumn{2}{|c|}{ Cold fluid single phase } \\
\hline Heat transfer & Gnielinski [36] \\
\hline Friction & Blasius [37] \\
\hline \multicolumn{2}{|c|}{ Cold fluid two-phase } \\
\hline Heat transfer & Shah $[38]$ \\
\hline Friction & Müller-Steinhagen and Heck [39] \\
\hline
\end{tabular}

the heat exchanger, and the cold fluid local heat transfer coefficient and frictional pressure gradient may be computed similarly. Only in the two-phase region, in which the heat transfer coefficient is a function of the heat flux, the cell tube lengths must be computed by iteration.

Each region in the HRB (i.e economizer, evaporator, and superheater) is discretized individually. The number of cells in each region is matched according to each heat load percentage of the total. Each discrete cell is solved for the required cell flow length of the cold fluid by marching through each cell in the cold fluid flow direction. In the following, the solution progress for each cell is described:

1. Compute the required overall UA-value in each discrete cell $i$ by

$$
(U A)_{i}=\frac{\dot{Q}_{i}}{\hat{T}_{\mathrm{h}}-\hat{T}_{\mathrm{c}}}
$$

where $\hat{T}_{\mathrm{h}}$ and $\hat{T}_{\mathrm{c}}$ are the approximated cell average hot and cold temperatures, respectively, and $\dot{Q}_{i}$ the cell heat flow rate.

2. Compute the hot fluid heat transfer coefficient and frictional pressure gradient

3. Compute the cold fluid heat transfer coefficient (guess on the cell flow length of the cold stream to estimate an initial heat flux, if necessary)

4. Compute the overall UA-value per unit flow length of the cold stream by

$$
\left(U A^{\prime}\right)_{i}=\left[\frac{1}{h_{\mathrm{c}, i} \pi d N}+\frac{\ln (D / d)}{2 \pi k_{\mathrm{w}} N}+\frac{1}{h_{\mathrm{h}, i} \eta_{\mathrm{o}, i} A_{\mathrm{t}}^{\prime} N}\right]^{-1}
$$

where $h_{\mathrm{c}, i}, h_{\mathrm{h}, i}$, and $\eta_{\mathrm{o}, i}$ are the cold and hot fluid heat transfer coefficients and the hot side surface fin efficiency, respectively, all evaluated using approximated cell average properties, $d$ and $D$ are the inner and outer diameters, $k_{\mathrm{W}}$ is the tube thermal conductivity, $A_{\mathrm{t}}^{\prime}$ is the total outer surface area including fins per unit tube length, and $N$ is the number of parallel cold fluid circuits.

5. Solve for the cold stream flow length as

$$
L_{\mathrm{c}, i}=\frac{(U A)_{i}}{\left(U A^{\prime}\right)_{i}}
$$


6. If the cold fluid heat transfer coefficient is a function of heat flux, repeat steps 3 to 5 using the updated cold stream flow length until convergence. The total area is finally obtained by

$$
A_{\mathrm{t}}=\sum_{i=1}^{n} A_{\mathrm{t}}^{\prime} N L_{\mathrm{c}, i}
$$

7. Compute auxiliaries such as the number of tube rows, the cold fluid pressure drop, and the hot fluid pressure drop.

\subsection{HRB Model Verification}

The model is verified with numerical results obtained from Stecco and Desideri [6] at 0.7 ammonia mass fraction while using the same transport property methods. No experimental results have been found that are suitable for a HRB validation. Nevertheless, the model agrees well with the obtained numerical results as depicted in Table 3 for several important parameters. The total heat transfer surface area is predicted within $6 \%$. The heat transfer coefficients match well for both the cold and hot fluids and show less than $4 \%$ deviation, except that of the cold fluid in the superheater which is over-predicted by $261 \%$. The cold fluid pressure drop is also over predicted in the superheater by $130 \%$. The results by Stecco and Desideri [6] indicate that the circuitry (or geometry) must have been altered entering the superheater, such that the cold fluid mass flux decreases. Otherwise, the pressure drop cannot be lower than in the evaporator for approximately the same heat exchanger size. In the current model, the cold fluid inlet and outlet velocities were 0.48 and $33.05 \mathrm{~m} \cdot \mathrm{s}^{-1}$, respectively. The latter, which is close to typical upper limits, could have been reduced by simply splitting the cold streams, e.g. into twice as many parallel circuits, but it was not chosen because the pressure drop is of secondary interest in this work. Nevertheless, the total hot fluid pressure drop matches well, and the deviation is within $10 \%$ error.

Fig. 7 shows the computed temperature profiles of the cold fluid, the hot fluid, and the tube wall externally. It indicates that for this HRB, the hot fluid gas-side controls the heat transfer process, since the wall temperature is close to that of the cold fluid. In other words, the heat transfer resistance is highest on the gas-side. Hence, the effects of different transport property methods used for the cold fluid ammonia-water mixture may have less importance for the HRB. This will be discussed in more detail in Sect. 4.

\subsection{OBB Model}

A sketch of the OBB is shown in Fig. 8. The OBB is recognized as several shell and tube heat exchangers having 1 shell pass for the hot fluid and 1 tube pass for the cold fluid. The tubes have circular fins and no tubes are placed in the window section. These options serve to enhance the heat transfer on the oil side while maintaining a low pressure drop. The hot fluid is Therminol 66, and the properties are obtained from Solutia Inc. [40]. The conditions are almost the same as for the HRB, except that the cold fluid and the hot fluid inlet temperatures are $50^{\circ} \mathrm{C}$ and $320^{\circ} \mathrm{C}$, respectively. 
Table 3 HRB model verification with results by Stecco and Desideri [6]; $Z=0.7, p_{\mathrm{c}}=40$ bar

\begin{tabular}{lrrl}
\hline & Current & Ref. [6] & Units \\
\hline Heat exchange in EC & 7.8 & 6.7 & $\mathrm{MW}$ \\
Heat exchange in EV & 31.1 & 32.1 & $\mathrm{MW}$ \\
Heat exchange in SH & 17.4 & 17.1 & $\mathrm{MW}$ \\
Total heat exchange & 56.2 & 55.9 & $\mathrm{MW}$ \\
Cold fluid mass flow & 19.49 & 19.12 & $\mathrm{~kg} \cdot \mathrm{s}^{-1}$ \\
\hline Average $h_{\mathrm{c}}$ in EC & 2638 & 2606 & $\mathrm{~W} \cdot \mathrm{m}^{-2} \cdot \mathrm{K}^{-1}$ \\
Average $h_{\mathrm{c}}$ in EV & 9692 & 10000 & $\mathrm{~W} \cdot \mathrm{m}^{-2} \cdot \mathrm{K}^{-1}$ \\
Average $h_{\mathrm{c}}$ in SH & 1662 & 460 & $\mathrm{~W} \cdot \mathrm{m}^{-2} \cdot \mathrm{K}^{-1}$ \\
Average $h_{\mathrm{h}}$ in EC & 36.2 & 34.9 & $\mathrm{~W} \cdot \mathrm{m}^{-2} \cdot \mathrm{K}^{-1}$ \\
Average $h_{\mathrm{h}}$ in EV & 41.6 & 40.7 & $\mathrm{~W} \cdot \mathrm{m}^{-2} \cdot \mathrm{K}^{-1}$ \\
Average $h_{\mathrm{h}}$ in SH & 47.6 & 47.3 & $\mathrm{~W} \cdot \mathrm{m}^{-2} \cdot \mathrm{K}^{-1}$ \\
\hline Heat transfer surface area in EC & 17774 & 11530 & $\mathrm{~m}{ }^{2}$ \\
Heat transfer surface area in EV & 14778 & 12901 & $\mathrm{~m}{ }^{2}$ \\
Heat transfer surface area in SH & 8619 & 14479 & $\mathrm{~m}{ }^{2}$ \\
Total heat transfer surface area & 41171 & 38910 & $\mathrm{~m}{ }^{2}$ \\
Number of tube rows & 69.6 & & \\
\hline Cold fluid pressure drop in EC & 0.09 & 0.77 & $\mathrm{bar}$ \\
Cold fluid pressure drop in EV & 0.70 & 1.68 & $\mathrm{bar}$ \\
Cold fluid pressure drop in SH & 1.26 & 0.55 & $\mathrm{bar}$ \\
Cold fluid total pressure drop & 2.05 & 3.00 & $\mathrm{bar}$ \\
Hot fluid pressure drop in EC & 0.0057 & 0.0029 & $\mathrm{bar}$ \\
Hot fluid pressure drop in EV & 0.0077 & 0.0055 & $\mathrm{bar}$ \\
Hot fluid pressure drop in SH & 0.0067 & 0.0086 & $\mathrm{bar}$ \\
Hot fluid total pressure drop & 0.0187 & 0.0171 & $\mathrm{bar}$ \\
\hline
\end{tabular}

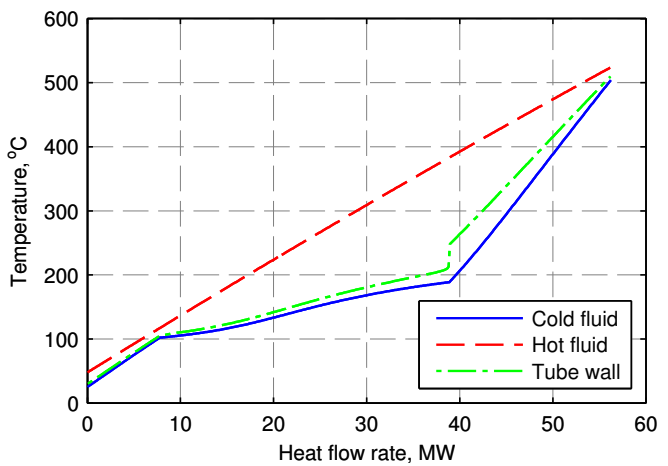

Fig. $7 \mathrm{HRB}$ temperature profiles as function of heat flow rate; $Z=0.7, p_{\mathrm{c}}=40$ bar

Again, the temperature profiles of both fluids as a function of the heat flow rate may be constructed (see Fig. 9), and the OBB remains to be designed to find the required heat exchanger surface area.

The model of the OBB is identical to the verified model of the HRB from Sect. 3.1 , except that the heat transfer coefficient and pressure drop on the shell side are 


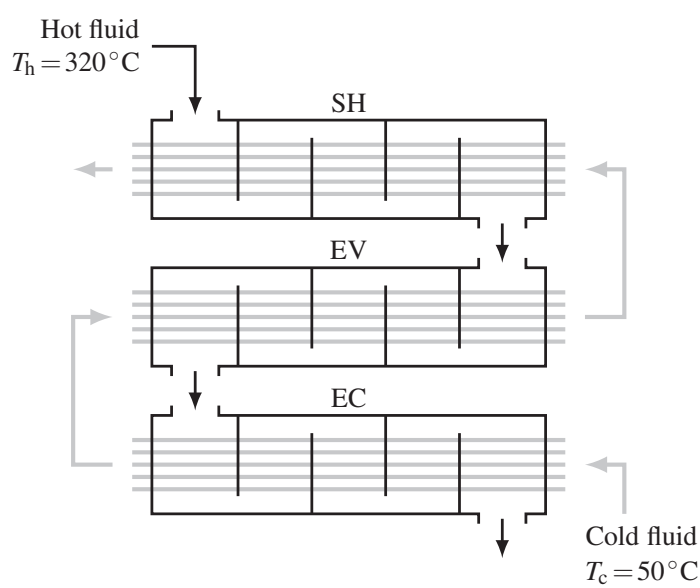

Fig. 8 Oil-based boiler

Table 4 Main geometry of the OBB

\begin{tabular}{lr}
\hline Number of parallel tubes & 120 \\
Inner tube diameter & $34 \mathrm{~mm}$ \\
Outer tube diameter & $40.64 \mathrm{~mm}$ \\
Fin density & $236 \mathrm{~m}^{-1}$ \\
Fin height & $10 \mathrm{~mm}$ \\
Fin thickness & $1 \mathrm{~mm}$ \\
Tube pitch & $70 \mathrm{~mm}$ \\
Shell bundle clearance & $15 \mathrm{~mm}$ \\
Shell inside diameter & $1014 \mathrm{~mm}$ \\
Central baffle spacing & $507 \mathrm{~mm}$ \\
Baffle cut ratio & 0.20 \\
Tube to baffle hole clearance & $0.8 \mathrm{~mm}$ \\
Shell to baffle hole clearance & $1.6 \mathrm{~mm}$ \\
\hline
\end{tabular}

computed differently. The Bell-Delaware method as extended by Taborek [41] has been used to establish the heat transfer coefficient and pressure drop on the shell side. In fact, the ideal heat transfer coefficient and ideal pressure drop (ideal tube bundle cross flow through the centerline of the shell) are computed with the same correlations as for the HRB (Table 2), however corrected for non-ideal shell flow effects using the Bell-Delaware method. Note that the entrance and exit baffle spacing effects have been neglected for simplicity. The specific geometry of the OBB is listed in Table 4. Additionally, the staggered rotated square layout is used, and the tube material is steel.

Note that the number of parallel tubes has increased compared to the HRB from 60 to 120 . This was chosen in order to keep the shell length-to-diameter ratio reasonably low, thus reducing the resulting hot fluid flow length and corresponding pressure drop.

Table 5 shows the numerical results of the OBB simulation at an ammonia mass fraction and pressure of 0.7 and $40 \mathrm{bar}$, respectively. The same transport property 
methods as used by Stecco and Desideri [6] are used to ensure a direct comparison with the HRB results from the previous section.

Table 5 OBB model results; $Z=0.7, p_{\mathrm{c}}=40$ bar

\begin{tabular}{lrl}
\hline Heat exchange in EC & 6.5 & MW \\
Heat exchange in EV & 38.1 & MW \\
Heat exchange in SH & 7.9 & MW \\
Total heat exchange & 52.4 & $\mathrm{MW}$ \\
Cold fluid mass flow & 23.9 & $\mathrm{~kg} \cdot \mathrm{s}^{-1}$ \\
\hline Average $h_{\mathrm{c}}$ in EC & 2063 & $\mathrm{~W} \cdot \mathrm{m}^{-2} \cdot \mathrm{K}^{-1}$ \\
Average $h_{\mathrm{c}}$ in EV & 10019 & $\mathrm{~W} \cdot \mathrm{m}^{-2} \cdot \mathrm{K}^{-1}$ \\
Average $h_{\mathrm{c}}$ in SH & 1106 & $\mathrm{~W} \cdot \mathrm{m}^{-2} \cdot \mathrm{K}^{-1}$ \\
Average $h_{\mathrm{h}}$ in EC & 213 & $\mathrm{~W} \cdot \mathrm{m}^{-2} \cdot \mathrm{K}^{-1}$ \\
Average $h_{\mathrm{h}}$ in EV & 302 & $\mathrm{~W} \cdot \mathrm{m}^{-2} \cdot \mathrm{K}^{-1}$ \\
Average $h_{\mathrm{h}}$ in SH & 350 & $\mathrm{~W} \cdot \mathrm{m}^{-2} \cdot \mathrm{K}^{-1}$ \\
\hline Heat transfer surface area in EC & 2706 & $\mathrm{~m}$ \\
Heat transfer surface area in EV & 3853 & $\mathrm{~m}$ \\
Heat transfer surface area in SH & 1684 & $\mathrm{~m}$ \\
Total heat transfer surface area & 8243 & $\mathrm{~m}$ \\
\hline Cold fluid total pressure drop & 0.18 & $\mathrm{bar}$ \\
Hot fluid total pressure drop & 1.16 & $\mathrm{bar}$ \\
\hline
\end{tabular}

The heat exchanged in the OBB is similar to the heat exchanged in the HRB (see Table 3). Less heat is however exchanged in the superheater, because the hot fluid inlet temperature is only $320^{\circ} \mathrm{C}$ in the OBB compared with $524^{\circ} \mathrm{C}$ in the $\mathrm{HRB}$. The cold fluid mass flow rate is also increased slightly. The heat transfer coefficients of the cold fluid are reduced because of the higher number of parallel tubes, thus reducing the ammonia-water velocity, i.e. 0.31 and $14.2 \mathrm{~m} \cdot \mathrm{s}^{-1}$ for the inlet liquid and outlet vapor, respectively. The hot fluid heat transfer coefficients are increased by a factor of 10 , because of the better heat transfer characteristics of the oil compared with the flue-gas. The required surface area is reduced to approximately one fifth of the HRB result. Finally, the hot fluid pressure drop becomes 1.16 bar while the cold fluid pressure drop results in 0.18 bar.

Fig. 9 shows the resulting temperature profiles of the OBB simulation including the external wall temperature. These profiles indicate that the heat transfer resistances on both sides of the heat exchanger are more similar than that in the HRB result in Fig. 7. In other words, the wall temperature profile becomes closer to the average of the cold and the hot fluid throughout the heat exchanger. It is therefore expected that the OBB will be more sensitive than the HRB towards the different transport property methods and their influence on the required heat exchanger surface area. This is discussed in detail in Sect. 4. 


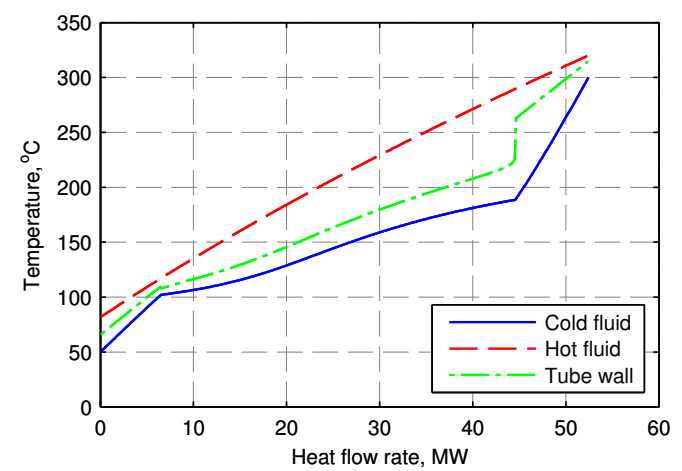

Fig. 9 OBB temperature profiles as function of heat flow rate; $Z=0.7, p_{\mathrm{c}}=40 \mathrm{bar}$

\subsection{Convergence}

The convergence rates of both models were also considered in order to estimate a suitable number of cells and approximative method for the cell center average properties (e.g. used in Eq. 2). The total number of cells was varied from 60 to 3840 cells, and the relative error in the predicted total surface area compared to the finest grid is shown in Fig. 10 for both the $1^{\text {st }}$ order accurate upwind approximation and the $2^{\text {nd }}$ order accurate midpoint rule approximation.

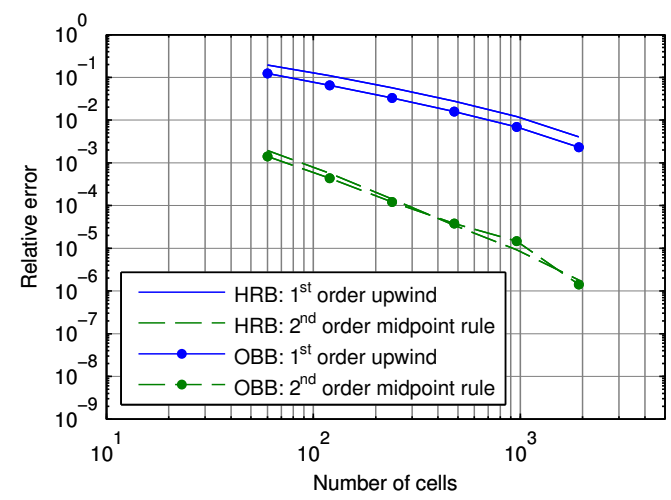

Fig. 10 Convergence rate using the $1^{\text {st }}$ order upwind approximation and the $2^{\text {nd }}$ order midpoint rule approximation, $Z=0.7, p_{\mathrm{c}}=40 \mathrm{bar}$

The average convergence rates are shown to compare against the expected order of accuracy for both the HRB and the OBB model. The upwind approximation leads to even more computation cells than shown, if a reasonable error in the predicted surface area must be attained. For having the five first digits converged in the predicted 
Table 6 HRB highest and lowest predicted areas and differences; $Z=0.7, p_{\mathrm{c}}=40 \mathrm{bar}$

\begin{tabular}{llllcc}
\hline \multicolumn{2}{c}{ Liscosity } & \multicolumn{1}{c}{ Vapor } & \multicolumn{2}{c}{ Liquid } & \multicolumn{2}{c}{ Vapor } & $\begin{array}{c}\text { Total Area } \\
{\left[\mathrm{m}^{2}\right]}\end{array}$ & $\begin{array}{c}\text { Difference } \\
{[\%]}\end{array}$ \\
\hline Stecco and Desideri [6] & Wilke [21] & Jamieson et al. [28] & Mason and Saxena [25] & 41196 & 1.48 \\
Stecco and Desideri [6] & Wilke [21] & Jamieson et al. [28] & Mole-average & 41195 & 1.48 \\
Stecco and Desideri [6] & Chung et al. [17, 18] & Jamieson et al. [28] & Mason and Saxena [25] & 41171 & 1.42 \\
Stecco and Desideri [6] & Chung et al. [17, 18] & Jamieson et al. [28] & Mole-average & 41170 & 1.41 \\
\hline Hdb Kältetechnik [24] & Reichenberg [20] & El-Sayed [11] & Mason and Saxena [25] & 40072 & -1.29 \\
Hdb Kältetechnik [24] & Reichenberg [20] & El-Sayed [11] & Mole-average & 40071 & -1.29 \\
Hdb Kältetechnik [24] & Chung et al. [17, 18] & El-Sayed [11] & Chung et al. [17, 18] & 40050 & -1.34 \\
Hdb Kältetechnik [24] & Reichenberg [20] & El-Sayed [11] & Chung et al. [17, 18] & 40045 & -1.36 \\
\hline
\end{tabular}

surface area and using the midpoint rule approximation, we must choose at least 1000 cells. For that reason, we used 2000 cells in all the simulations herein to be certain that the predicted areas are converged.

\section{Results}

In this section, the influence of the transport property methods on the predicted heat transfer surface area is reported for both the HRB and the OBB. Three methods from Sect. 2.1 to 2.4 each (Figs. 2 to 5), i.e. 12 methods in total, are simulated for all combinations. The Chung et al. $[17,18]$ composition-averaged error methods were excluded for the vapor viscosity and the thermal conductivity, because these methods are more computationally intensive than all other methods and therefore not considered to be beneficial for numerical simulation and design. Additionally, coinciding methods were excluded for the liquid viscosity and thermal conductivity, namely the methods by El-Sayed [11] and Filippov [27], respectively.

\subsection{HRB Results}

Table 6 shows the four highest and lowest predicted areas for the HRB at an ammonia mass fraction and cold fluid pressure of 0.7 and $40 \mathrm{bar}$, respectively. Additionally, the area difference with respect to the mean area $\left(\Delta A_{t} / \bar{A}_{t}\right)$ is given. Referring to Figs. 2 to 5 , the general trend in these results is that an increased thermal conductivity decreases the predicted area, while an increased viscosity increases the predicted area. This observation may be explained by reviewing the simple single phase Dittus-Boelter equation [42], for which the heat transfer coefficient is isolated

$$
\begin{aligned}
h & =\frac{\mathrm{Nu} k}{d}=C \operatorname{Re}^{m} \operatorname{Pr}^{n} \frac{k}{d} \\
& =C\left(\frac{G d}{\mu}\right)^{m}\left(\frac{c_{\mathrm{p}} \mu}{k}\right)^{n} \frac{k}{d} \\
& =f\left(\mu^{n-m}, k^{1-n}, \ldots\right)
\end{aligned}
$$

where $m=0.8, n=0.4$, and $C$ is a constant. Thus the exponent of viscosity $\mu$ is negative while that of thermal conductivity $k$ is positive in the computation of the single 
phase heat transfer coefficient. The boiling two-phase flow heat transfer coefficient is more complex to analyze similarly. However, the same trend should be expected at least for the convective boiling contribution.

The predicted areas are very similar, and the maximum difference is only $1.48-(-1.36)=2.84 \%$. This result may change if the ammonia-water composition is changed, or if the ammoniawater pressure is increased (e.g. see Fig. 4b) or if the gas-side heat transfer resistance is reduced. The latter means that the importance of the ammonia-water heat transfer characteristics is increased. All these effects are essentially gathered in Fig. 11, which shows the maximum area difference as a function of ammonia mass fraction at different cold fluid pressures and hot fluid frontal areas (individual tube lengths are halved). Note that the maximum area difference is the difference between the highest and lowest predicted areas with respect to the mean area $\left(\Delta A_{\mathrm{t}, \max } / \bar{A}_{\mathrm{t}}\right)$, and that the mean area becomes different for each conditions $\left(Z, p_{\mathrm{c}}\right.$, and $\left.L_{\text {tube }}\right)$.

Fig. 11 indicates that the maximum difference increases with increased ammoniawater pressure and increases with decreased hot fluid frontal area. The former is a result of the transport property methods for ammonia-water that deviate more at higher boiler pressures (and higher liquid temperatures), while the latter increases the influence of the ammonia-water heat transfer characteristics. Nevertheless, the maximum area difference is smaller than $4.3 \%$ for these HRB configurations and conditions.

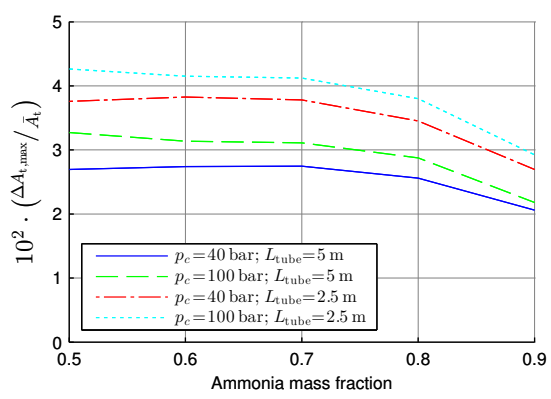

Fig. 11 HRB maximum area difference vs. ammonia mass fraction

\subsection{OBB Results}

Fig. 12 indicates the maximum area differences for the OBB as a function of the ammonia mass fraction and pressure. The area differences are increased compared to the HRB, because the heat transfer characteristics of the oil are better than those of the flue-gas. The result is that the ammonia-water heat transfer characteristics become more important. The maximum area difference is $12.3 \%$ for the investigated OBB conditions. Again, an increased pressure of the ammonia-water mixture results in larger area differences. 


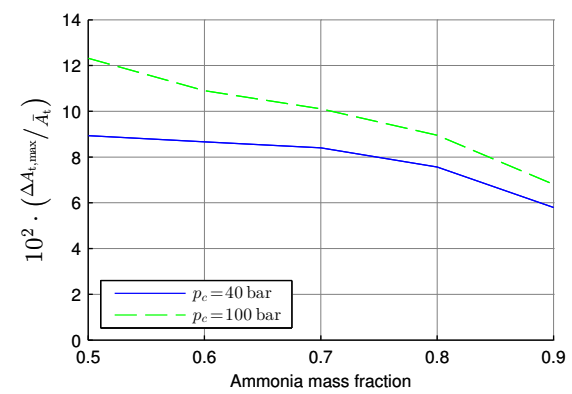

Fig. 12 OBB maximum area difference vs. ammonia mass fraction

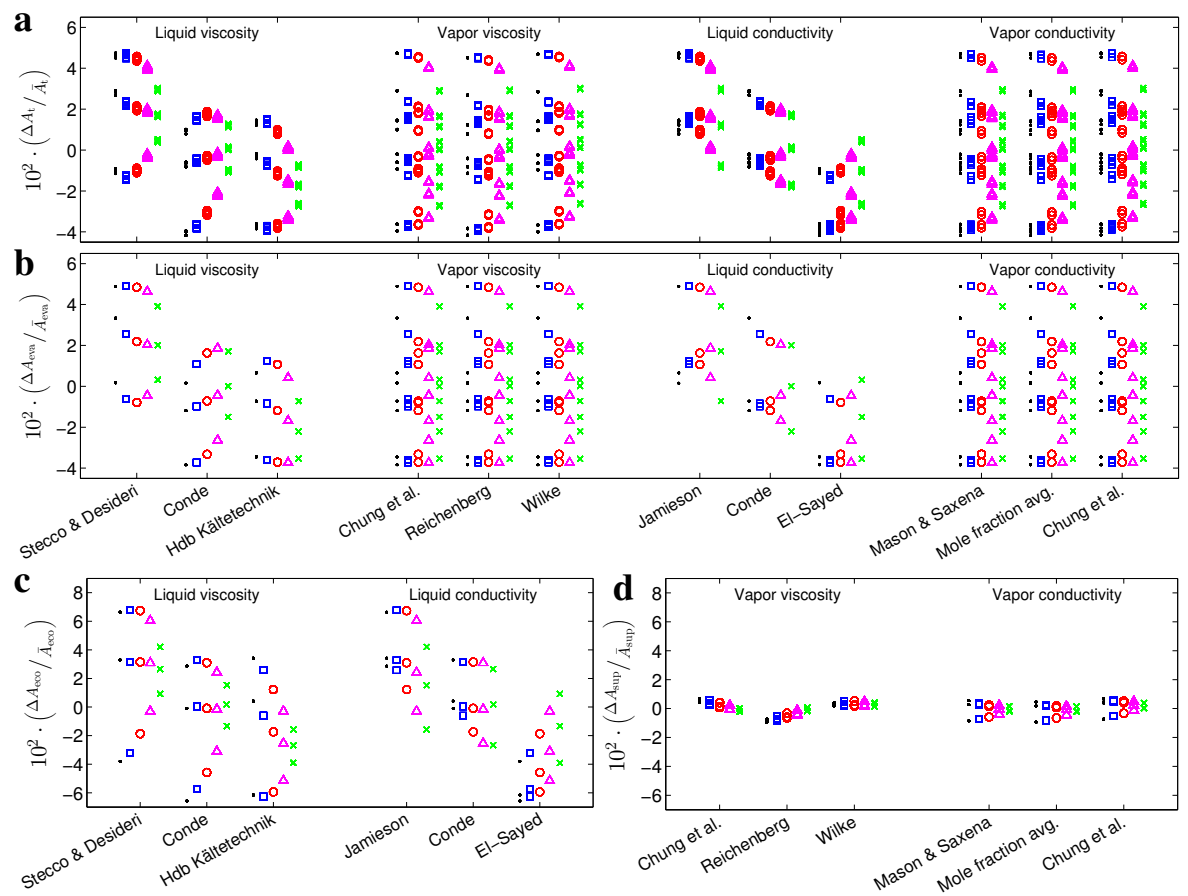

Fig. 13 OBB area differences specific to each transport property method; $p_{\mathrm{c}}=40$ bar; (a) total area, (b) evaporator area, (c) economizer area, and (d) superheater area. $\bullet Z=0.5 ; \square Z=0.6 ; \circ Z=0.7 ; \Delta Z=0.8$; $\times Z=0.9$

Fig. 13 shows the area differences for the OBB specific to each transport property method for the total boiler area and each individual part (economizer, evaporator, and superheater) at a pressure of 40 bar and at all ammonia-water mass fractions considered herein. Note that the results of all the transport property combinations $\left(3^{4}=81\right)$ and all the ammonia-water mass fractions $(81 \times 5=405)$ are shown for each of the four transport properties (liquid and vapor viscosity and thermal conductivity) in Figs. 13a and 13b. In contrast, Fig. 13c shows only the liquid property combi- 
nations $\left(3^{2} \times 5=45\right)$, while Fig. $13 \mathrm{~d}$ shows only the vapor property combinations $\left(3^{2} \times 5=45\right)$.

Fig. 13d indicates that the vapor transport property methods have little influence on the required heat transfer surface area $(\approx 1-2 \%)$ of the superheater. This fact is also indicated in Figs. 13a and 13b for the total and evaporator area, respectively. Here the area differences do not change much when changing the vapor transport property method.

On the other hand, the liquid transport property methods show larger area differences as indicated in Fig. 13c for the economizer. These area differences are smaller for the total and evaporator area (Figs. 13a and 13b), however they show a similar trend. Hence, the results in Fig. 13 suggest that the liquid properties have the highest impact on the heat exchanger area estimation.

The trend in the results is the same for the 100 bar conditions, and also the same for the HRB simulations; i.e. the liquid property methods matter the most. Fig. 13a indicates that the highest boiler area is achieved when the liquid viscosity method by Stecco and Desideri [6] and the liquid conductivity method by Jamieson et al. [28] are used. This is the same result as indicated in Table 6 for the HRB. Furthermore, the lowest boiler area in Fig. 13a (at $Z=0.7$ ) occurs when using the liquid viscosity method proposed in Handbuch der Kältetechnik [24] and the liquid conductivity method by El-Sayed [11]. Again, the same result is suggested in Table 6 for the HRB.

\section{Discussion}

The work by Thorin [9] suggests that the use of different transport property methods may lead to differences as much as $10 \%$ in the predicted heat transfer area. It should be noted that the $10 \%$ refers to individual heat exchangers and not the HRB or the total heat transfer area in the author's Kalina cycle configuration. Only $0.64 \%$ area difference was associated with the HRB, while half of the total area was used for that component. Moreover, $3 \%$ area difference was associated with the total heat transfer area.

The current comparison shows a much higher difference for the HRB than in the work by Thorin [9] $(4.3 \% \gg 0.64 \%)$. Thorin [9] used an ammonia-water pressure of 108 bar. However, no information was given on the heat exchanger geometry such as fins and frontal areas. The latter issue makes it difficult to compare the results directly. Additionally, Thorin [9] used a constant boiling heat transfer coefficient of $10 \mathrm{~kW} \cdot \mathrm{m}^{-2} \cdot \mathrm{K}^{-1}$.

The HRB is usually gas-side controlled, reducing the effects of the ammoniawater heat transfer characteristics. On the other hand, the heat transfer resistances on both fluid sides are more evenly distributed. Nevertheless, the influence of using different transport property methods resulted in less than $12.3 \%$ predicted area difference during the OBB design. In the light of typical uncertainties in the heat transfer correlations for both single and two-phase flows, the result is encouraging, because it indicates that the use of different ammonia-water transport property methods has a minor significance during heat exchanger design. The vapor methods showed nearly similar results, while the liquid methods appeared to have higher significance. It is 
however believed that the recuperators in Kalina cycles may show larger area differences, because these have the ammonia-water mixtures on both sides of the heat exchanger.

For the above reasons, it cannot be claimed that some methods necessarily are more appropriate to use than others. Nevertheless, a few preliminary guidelines are provided in the following. For the liquid viscosity and thermal conductivity, the authors' suggest the use of the methods by Conde-Petit [1]. These methods compare the best with the experimental data in Fig. 3a, 5a and 5b, although the thermal conductivity data show a large scatter. Furthermore, these methods are smooth and continuous in the investigated temperature range. For the vapor viscosity and thermal conductivity, the authors' suggest use of the methods by Wilke [21] and Mason and Saxena [25], tentatively, when a dynamic simulation is not performed. For dynamic simulation, a continuous first derivative is imperative, and the user should choose the corresponding state methods by Chung et al. [17, 18]. The methods by Wilke [21] and Mason and Saxena [25] were also proposed by Conde-Petit [1] and El-Sayed [11].

Many boiling heat transfer correlations have been proposed for binary mixtures, and these should also be assessed with regards to their significance on the predicted heat transfer area during design to achieve a full evaluation of ammonia-water mixture effects. These heat transfer correlations typically suggest high degradation for wide-boiling mixtures, thus leading to a higher heat transfer surface area. In this study, the Shah [38] correlation was used including mixture properties. The correlation was not specially developed for mixtures, but has been shown to agree reasonably well for refrigerant mixtures [7]. However, it does not include the nucleate boiling suppression due to mass diffusion. It is a topic of interest in future work of our research.

\section{Conclusion}

This paper presents a systematic numerical analysis of several transport property methods applicable to ammonia-water mixtures in an attempt to quantify their individual influence during heat exchanger design. Two design studies related to the use of the Kalina cycle were considered for this purpose: a flue-gas-based heat recovery boiler (HRB) for a combined cycle power plant and a hot-oil-based boiler (OBB) for a solar thermal power plant.

From the heat exchanger design simulations, it may be concluded that the transport property methods resulted in minor differences in the predicted heat transfer area. The maximum predicted heat transfer area differences were $4.3 \%$ and $12.3 \%$ for the HRB and the OBB, respectively. These simulations were performed at various ammonia-mass fractions ( 0.5 to 0.9 ) and pressures (40 to 100 bar). Additionally, the gas-side heat transfer resistance was reduced by halving the gas-side frontal area for the HRB.

The design simulations indicate that the liquid transport property methods result in more of the area differences than the vapor transport property methods. Additionally, the area difference increases at higher boiler pressures. 
Finally, it is shown that the interpolative methods may show a discontinuous first derivative in contrast to the fully predictive corresponding state methods. The discontinuity occurs as the pure components need to be restricted to be in the same phase as the mixture.

\section{A Transport Property Methods}

The Appendix includes all the equations that are used to estimate the transport properties used in this work, see Table 7 and 8 , with the exception of the mixing rules and the constant coefficients used in the methods by Chung et al. $[17,18]$. Index " 1 " refers to ammonia and index " 2 " refers to water, except in the methods by Reichenberg [20] and Filippov [27] for which index "2" refers to the fluid with the highest thermal conductivity.

Table 7 Liquid transport property methods

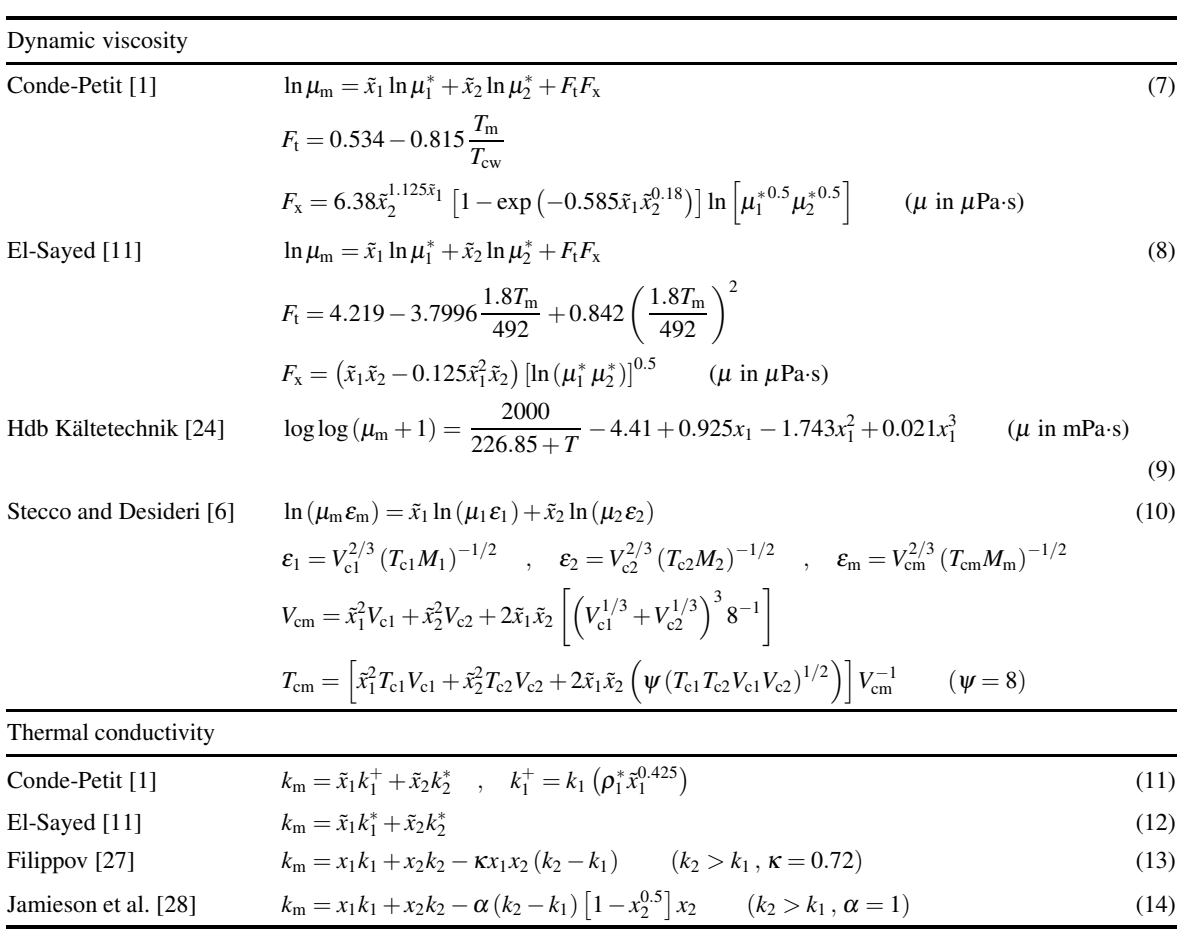

\section{References}

1. M. Conde-Petit, Thermophysical Properties of NH3+H2O Mixtures for the Industrial Design of Absorption Refrigeration Equipment (Zurich, Switzerland, 2006). URL http://www.mrc-eng.com. Accessed 26 January 2015 
Table 8 Vapor transport property methods

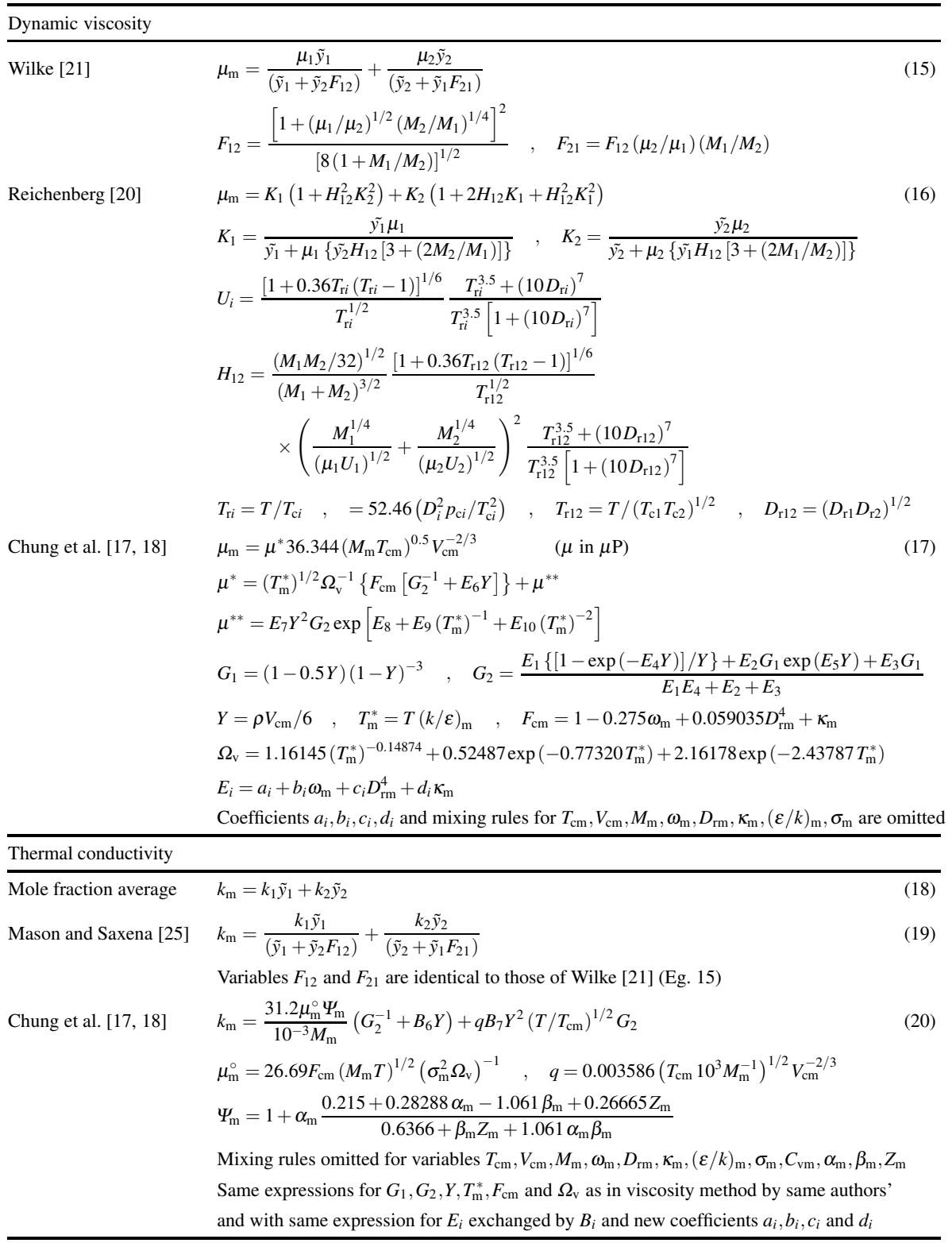

2. J. Liu, S. Wang, A. Hartono, H.F. Svendsen, C. Chen, J. Chem. Eng. Data 57(9), 2387 (2012). DOI $10.1021 / \mathrm{je} 300102 \mathrm{~d}$

3. Y. Cuenca, D. Salavera, A. Vernet, M. Vallès, Int. J. Refrig. 36, 998 (2013). DOI 10.1016/j.ijrefrig.2012.10.039 
4. F.N. Shamsetdinov, Z.I. Zaripov, I.M. Abdulagatov, M.L. Huber, F.M. Gumerov, F.R. Gabitov, A.F. Kazakov, Int. J. Refrig. 36, 1347 (2013). DOI 10.1016/j.ijrefrig.2013.02.008

5. E.W. Lemmon, M.L. Huber, M.O. Mclinden, NIST Standard Reference Database 23: Reference Fluid Thermodynamic and Transport Properties - REFPROP 9.12 (National Institute of Standards and Technology, Boulder, Colorado, USA, 2013)

6. S.S. Stecco, U. Desideri, J. Eng. Gas Turbines Power 114(4), 701 (1992). DOI doi:10.1115/1.2906645

7. D.S. Jung, M. McLinden, R. Radermacher, D. Didion, Int. J. Heat Mass Transf. 32(9), 1751 (1989). DOI 10.1016/0017-9310(89)90057-4

8. G.P. Celata, M. Cumo, T. Setaro, Exp. Therm. Fluid Sci. 9(4), 367 (1994). DOI 10.1016/08941777(94)90015-9

9. E. Thorin, Int. J. Thermophys. 22(1), 201 (2001). DOI 10.1023/A:1006745100278

10. R. Tillner-Roth, D. Friend, J. Phys. Chem. Ref. data 27(1), 63 (1998). DOI http://dx.doi.org/10.1063/1.556015

11. Y. El-Sayed, Winter Annu. Meet. Am. Soc. Mech. Eng. pp. 19-24 (1988)

12. A. Modi, F. Haglind, Appl. Therm. Eng. 65(1-2), 201 (2014). DOI 10.1016/j.applthermaleng.2014.01.010

13. E.W. Lemmon, Private communication (National Institute of Standards and Technology, Boulder, Colorado, USA, 2013)

14. A. Modi, F. Haglind, Appl. Therm. Eng. 76, 196 (2015). DOI 10.1016/j.applthermaleng.2014.11.047

15. C.L. Sassen, R.A.C. van Kwartel, H.J. van Der Kooi, J. de Swaan Arons, J. Chem. Eng. Data 35, 140 (1990). DOI 10.1021/je00060a013

16. B.E. Poling, J.M. Prausnitz, J.P. O'Connell, The Properties of Gases and Liquids, 5th edn. (McGrawHill, New York, USA, 2001)

17. T.H. Chung, L.L. Lee, K.E. Starling, Ind. \& Eng. Chem. Fundam. 23, 8 (1984). DOI $10.1021 / \mathrm{i} 100013 \mathrm{a} 002$

18. T.H. Chung, M. Ajlan, L.L. Lee, K.E. Starling, Ind. \& Eng. Chem. Res. 27(4), 671 (1988). DOI 10.1021/ie00076a024

19. A.S. Teja, P. Rice, Ind. \& Eng. Chem. Fundam. 20(1), 77 (1981). DOI 10.1021/i100001a015

20. D. Reichenberg, New simplified methods for the estimation of the viscosities of gas mixtures at moderate pressures (National Physical Laboratory, Division of Chemical Standards, East Kilbride, Glasgow, Scotland, 1977)

21. C.R. Wilke, J. Chem. Phys. 18(4), 517 (1950). DOI 10.1063/1.1747673

22. M.J.W. Frank, J.A.M. Kuipers, W.P.M. van Swaaij, J. Chem. Eng. Data 41(2), 297 (1996). DOI $10.1021 / \mathrm{je} 950157 \mathrm{k}$

23. G. Pinewitsch. Cholodilnaja Technika 20(3), 30 (1948). Reproduced in Kältetechnik 2(2), 29 (1950)

24. R. Plank, F. Steimle, K. Stephan, Handbuch der Kältetechnik. - 6B: Wärmeaustauscher (Springer, Berlin, Germany, 1988)

25. E.A. Mason, S.C. Saxena, Phys. Fluids 1(5), 361 (1958). DOI 10.1063/1.1724352

26. A. Baranov, B. Churagulov, A. Kalina, F. Sharikov, A. Zharov, A. Yoroslavtsev, in Rep. Work. Thermophys. Prop. Ammon. Mix., ed. by W. Friend, D.G., Haynes (NISTIR 5059, Boulder, Colorado, USA, 1997), pp. 59-67

27. L. Filippov, Ser. Fiz. Mat. Estestv. Nauk 10, 67 (1955)

28. D.T. Jamieson, J.B. Irving, J.S. Tudhope, Liquid thermal conductivity. A data survey to 1973 (Edinburgh, Scotland, 1975)

29. Dymola 2014. Dynamic Modeling Laboratory, Dassault Systemes AB, Research Park Ideon SE-223 70, Lund, Sweden (2014)

30. J. Wronski, M.R. Kærn, H. Francke, REFPROP2Modelica (Technical University of Denmark and GFZ Potsdam, 2014). URL https://github.com/jowr/REFPROP2Modelica. Accessed 26 January 2015

31. M.B. Ibrahim, R.M. Kovach, Energy 18(9), 961 (1993). DOI 10.1016/S0360-5442(06)80001-0

32. P. Nag, A. Gupta, Appl. Therm. Eng. 18(6), 427 (1998). DOI 10.1016/S1359-4311(97)00047-1

33. D.E. Briggs, E.H. Young, Chem. Eng. Prog. Symp. Ser. 59(41), 1 (1963)

34. R.K. Shah, D.P. Sekulic, Fundamentals of heat exchanger design (John Wiley \& Sons, Hoboken, New Jersey, USA, 2003)

35. K.K. Robinson, D.E. Briggs, Chem. Eng. Prog. Symp. Ser. 62(64), 177 (1966)

36. V. Gnielinski, Int. Chem. Eng. 16, 359 (1976)

37. H. Blasius, in Mitteilungen über Forschungsarbeiten auf dem Gebiete des Ingenieurwesens 131 (Springer, Berlin, Germany, 1913), pp. 1-41

38. M.M. Shah, ASHRAE Trans. 88, 185 (1982) 
39. H. Müller-Steinhagen, K. Heck, Chem. Eng. Process. Process Intensif. 20, 297 (1986)

40. Solutia Inc., Therminol 66, High performance highly stable heat transfer fluid (2014). URL http://twt.mpei.ac.ru. Accessed 26 January 2015

41. J. Taborek, in Heat Exch. Des. Handb., ed. by G.F. Hewitt (Begell House, New York, USA, 1998), chap. 3, pp. 3.3.3-1 - 3.3.11-5

42. F.W. Dittus, L.M.K. Boelter, Univ. Calif. Publ. Eng. 2(13), 443 (1930) 